\title{
Trend and Change-Point Analysis of Streamflow and Sediment Discharge of the Gongshui River in China during the Last 60 Years
}

\author{
Li-Ping Guo ${ }^{1,2} \mathbb{1}$, Qiang Yu ${ }^{2}$, Peng Gao ${ }^{2}$, Xiao-Fei Nie ${ }^{1} \mathbb{1}$, Kai-Tao Liao ${ }^{1}$, Xiu-Long Chen ${ }^{1,2}$, \\ Jian-Min $\mathrm{Hu}^{3, *}$ and Xing-Min $\mathrm{Mu}^{2, *}$ \\ 1 Jiangxi Provincial Key Laboratory of Soil Erosion and Prevention, Jiangxi Institute of Soil and Water \\ Conservation, Nanchang 330029, China; guolp.10b@igsnrr.ac.cn (L.-P.G.); xfnie85@163.com (X.-F.N.); \\ 13755789403@126.com (K.-T.L.); chenxl.10b@igsnrr.ac.cn (X.-L.C.) \\ 2 State Key Laboratory of Soil Erosion and Dryland Farming on the Loess Plateau, Institute of Soil and Water \\ Conservation, Chinese Academy of Sciences and Ministry of Water Resources, Northwest A\&F University, \\ Yangling 712100, Shaanxi, China; yuqiang@igsnrr.ac.cn (Q.Y.); gaopeng@ms.iswc.ac.cn (P.G.) \\ 3 Jiangxi Provincial Institute of Water Sciences, Nanchang 330029, China \\ * Correspondence: hjmhx@jxsl.gov.cn (J.-M.H.); muxingmin@ms.iswc.ac.cn (X.-M.M.)
}

Received: 31 July 2018; Accepted: 14 September 2018; Published: 18 September 2018

\begin{abstract}
The Gongshui River basin exhibits one of the most serious soil erosion areas in southern China, and has always been the key control area of national soil and water conservation programs. This study used daily precipitation, streamflow, and sediment concentration data collected from 1957 to 2015 from the main hydrological stations of the Gongshui River to investigate streamflow and sediment discharge variations and their responses to precipitation and human activities. The Mann-Kendall and Pettitt's test were used for trend and change-point detection. The double mass curve (DMC) method was employed to quantify the effects of precipitation change and human activities on hydrological regime shifts. The results showed insignificant trends of both annual precipitation and streamflow for all stations, while the sediment discharge of most stations exhibited significant decreasing trends. Change-point analyses revealed that all hydrologic stations except Mazhou had transition years. The estimation via DMC indicated that after the change point years, there was a rapid reduction in sediment discharge at Hanlinqiao, Fengkeng, Julongtan, Xiashan, and Chawu stations, but not at Mazhou, Ruijin, and Yangxinjian stations. Human activity provided a significantly greater contribution to sediment discharge than precipitation. The evidence clearly indicates that the degree and extension of conservation or destruction measures and the construction of large- and medium-sized reservoirs were the major factors significantly decreasing or increasing annual sediment discharge of the Gongshui River. This work could serve as the basis for decision making regarding river basin water resources management to estimate the effects of anthropogenic impacts on water and sediment discharge variations during the last few decades, thereby guiding adaptation and protection of the water resources of the Gongshui River flowing into the Poyang Lake.
\end{abstract}

Keywords: streamflow; sediment discharge; human intervention; soil and water conservation; reservoir construction; non-parametric method; double mass curves; Gongshui River

\section{Introduction}

In the past half century, affected by global warming and frequent human activities, the natural balance of many basins in the world is changing gradually or abruptly, which has attracted worldwide attention [1]. Among them, the research on the trend of streamflow and sediment in the river basin, as well as the influence level and mechanism of climate change and human activities on these 
changes, has been a hot research topic in the fields of river geomorphology and water conservancy engineering [2]. In China, such research is mainly concentrated in major rivers and their tributaries, especially in the Yellow River and Yangtze River. Li et al. [3] investigated temporal trends and historical phases of sediment flux delivered to the sea by nine major rivers in China, and also quantified the contribution of key anthropogenic and natural driving forces, indicating that a reduction of sediment concentration dominates the sediment load decrease in China. Additionally, they demonstrated that reservoirs, especially large reservoirs, mainly reduce sediments in Chinese rivers, while soil conservation measures had enhanced the decrease in sediment flux after 1999. Zhao et al. [4] assessed the response of sediment load to climate change and human activities with six different methods in the Huangfuchuan watershed, a first-order tributary of the Yellow River in the northern Loess Plateau, China, and found that the sediment load exhibited a 70.5\% reduction, and human activities played a dominant role, accounting for $93.6 \pm 4.1 \%$ of the sediment load reduction. Wu et al. [5] applied ten commonly used quantitative methods drawn from three main categories-empirical statistics, elasticity-based methods, and hydrological modeling, to assess the impacts of climate change and human activities on runoff in the Yanhe River basin, and indicated that climate change had a larger effect on decreases in runoff, accounting for $54.1 \%$. As the longest river in Asia, the temporal change of sediment load and streamflow in the Yangtze River and possible causes and implications, have also received widespread attention [6], and a great deal of work has been done on the climate change and the influence of large-scale water conservancy projects (such as the South-to-North Water Transfer Project and the Three Gorges Project) on the trend of rainfall, runoff, sediment, and flood [7-14]. Significant and non-significant trends were detected for annual sediment discharge and runoff at all stations in the Yangtze River basin, respectively. Water reservoirs exerted more influence on changes of sediment discharge than on streamflow, which was the main reason for the decreasing trend of sediment discharge found in most stations $[7,10]$.

Poyang Lake is the largest freshwater lake in China, located in the north of Jiangxi province and along the south bank of the middle and lower reaches of the Yangtze River [15]. This area is a low mountainous and hilly region with serious water erosion of the typical red soil region (mainly including the red soil, brown-red soil, yellow-red soil, and red clay) in southern China, resulting in excess sediment loads in the Poyang Lake. Although there are lots of source areas for these sediment loads, the influx rivers contribute the majority. Among the five largest inflow rivers, Ganjiang River was considered as the largest contributor. As the upstream watershed of the Ganjiang River watershed, the Gongshui River watershed suffered serious soil erosion due to the vulnerable ecological environment and excess exploitation, especially in the 1960s to the early 1980s, and vast water and soil was lost [16]. A series of studies have been carried out in the area of the Poyang Lake Basin and its largest river (Ganjiang) in the last few decades, such as flood analysis, runoff over the land surface, the analysis of trends of streamflow and sediment delivery and their driving forces, spatio-temporal patterns of sediment and runoff changes and the underlying causes, influence of hydropower stations upstream of the river, and sediment adjustment [10,11,17-19]. Recent research results indicate that the changing patterns of annual streamflow (non-significant increasing trend) and sediment loads (significant negative change) are different in the Poyang Lake Basin and Ganjiang River $[11,17,20]$. Changes in the region include fluctuations in the duration and intensity of precipitation, comprehensive control of water-soil erosion, reservoir construction, land-use changes, etc. These changes have influenced the changes in annual runoff and sediment discharge into Poyang Lake, and the human activities have played a more important role in the last decades $[10,16,20,21]$. In particular, the forest coverage changes caused by artificial deforestation and reconstruction on vegetation have had significant impacts on sediment discharge, with no evident influence on runoff at the annual scale. Zhang et al. [8] estimated that the contributions of human activities and climate change to streamflow changes in the Poyang Lake basin were $73.2 \%$ and $26.8 \%$, respectively, whereas human-induced and climate-induced influences on streamflow were different in different river basins. Moreover, the construction of hydraulic facilities, especially their effect on sand interception by large- 
and medium-sized water reservoirs, is the major cause of the significantly decreasing sediment loads. The effect of reservoir construction on the changes in the weight of the sediment load entering the Poyang Lake is almost five times that of water and soil erosion [11,15,17,18].

There has been almost no research on the changes in the streamflow and sediment discharge on the smaller tributaries, especially for the Gongshui River, which provide useful information on the processes of soil erosion and sediment delivery [22]. Soil erosion is one of the most serious environmental problems in the survival and development of human society, which destroys land resources; pollutes water quality; silts up rivers, lakes, and reservoirs; and aggravates flood disasters, thus affecting the development of the ecological environment and socio-economy. Rainfall and increasing human activities are the main driving factors of the soil erosion. Specifically, integrated factors like abundant rainfall accompanied by high intensity rain storms in the flood season, low mountainous and hilly regions, great undulate terrain, man-made destruction like damaging forests to reclaim land, and cutting down the forest and grass as firewood for cooking and steelmaking fuel etc., make the basin of Gongshui River a typical vulnerable ecology region with serious soil erosion in southern China. National key regulation engineering efforts devoted to the control of soil erosion have been launched twice in the Gongshui River basin. The first phase of the regulation project was started in 1983 in Xingguo county of Pingiiang branch, and the second phase of the control process was expanded from Xingguo to Yudu, Ningdu, Ruijin, Huichang, and Shicheng counties, located at the middle and upper reaches of the Gongshui River in 1993, with work lasting for 10 years. In the period of key management of water-soil erosion, many measures such as afforestation and the construction of water storage projects, especially reservoirs and sand collection dams; planting soil and water conservation forests; economic forestry; and planting grasses and fruit-bearing trees, were carried out in this region $[19,23]$. Even after many decades, only a few studies on the effect of soil erosion control have been reported, especially for the studies of streamflow and sediment changes, which play important roles in shaping river morphology; providing water resources; and protecting, maintaining, and improving regional environments and ecosystems.

Therefore, this study is aimed at the analysis of the impacts of climate change and man-made activities on changes in the streamflow and sediment discharge with respect to the changes of flow direction and water velocity over the past 60 years. The objectives of this work were to: (a) conduct a trend and change-point analyses of streamflow and sediment discharge in the eight hydrological stations along the Gongshui River; (b) determine the main forces that drive these changes; and (c) estimate the impacts of precipitation and human activities on changes in streamflow or sediment discharge by comparing the period before and after the change-point. The results of this research could help watershed management decision makers in the area of Gongshui estimate the effects of climate change and anthropogenic factors (especially water-soil conservation measures, the construction of water supply and control projects, and land-use changes, etc.) on changes of water and sediment discharge in the region in the last few decades. Furthermore, the results of this study will be valuable in directing future work regarding the use and protection of water resources in the Gongshui River.

\section{Study Area and Data Sets}

This study was conducted in the Gongshui River Basin $\left(114^{\circ} 48^{\prime}-116^{\circ} 08^{\prime}\right.$ E, $\left.24^{\circ} 38^{\prime}-26^{\circ} 43^{\prime} \mathrm{N}\right)$ (Figure 1), which is located upstream of the Ganjiang, one of the eight major tributaries of the Yangtze River and the largest inflowing river of Poyang Lake. The total length of the main stream of Gongshui River is $313 \mathrm{~km}$. The river flows through 14 counties and cities, occupying an area of $27,074 \mathrm{~km}^{2}(30 \%$ of the Ganjiang River Basin) [23]. The climate of Gongshui River Basin belongs to that of the subtropical monsoon humid climate area, with an average annual precipitation of $1627 \mathrm{~mm}$, evaporation of $1550 \mathrm{~mm}$, and temperature of $18{ }^{\circ} \mathrm{C}$ [16]. The abundant rainfall is always concentrated in the flood season (from April to September), accompanied by high intensity rainstorms. Moreover, the Gongshui River Basin has staggered mountains and hills, greatly undulating terrain, and a large population 
density with prominent population-land conflicts. These combined factors make this area ecologically vulnerable with potentially serious soil erosion.


Figure 1. Location of study region and main hydrological stations in the Gongshui River.

The Gongshui River datasets of long-term daily flow and sediment content were provided by the Hydrology Bureau of Jiangxi Province; the precipitation data were from the National Meteorological Information Centre of the Chinese Meteorological Administration. There are 16 hydrological stations in the study area, and only eight stations in which both streamflow and sediment discharge data have been measured and documented. Among them, Mazhou and Ruijin hydrological stations are separately connected with Xiangshui and Mianshui Rivers; Hanlinqiao, Fengkeng, and Yangxinjian hydrological stations are close to the branches of Pingjiang, Meijiang, and Lianjiang Rivers; Julongtan and Chawu hydrological stations are both connected to Taojiang branch of Gongshui River; and Xiashan is a representative hydrological station of Gongshui. Most of the data sets cover more than 50 years, except for Ruijin and Chawu stations, with only 15 years of data available. The length of the Ruijin sediment dataset was 1964-1981. The corresponding statistical information for the upstream, midstream, and downstream hydrological stations is given in Table 1.

Table 1. Drainage area, average precipitation, annual streamflow, and sediment discharge of the hydrological stations on Gongshui River.

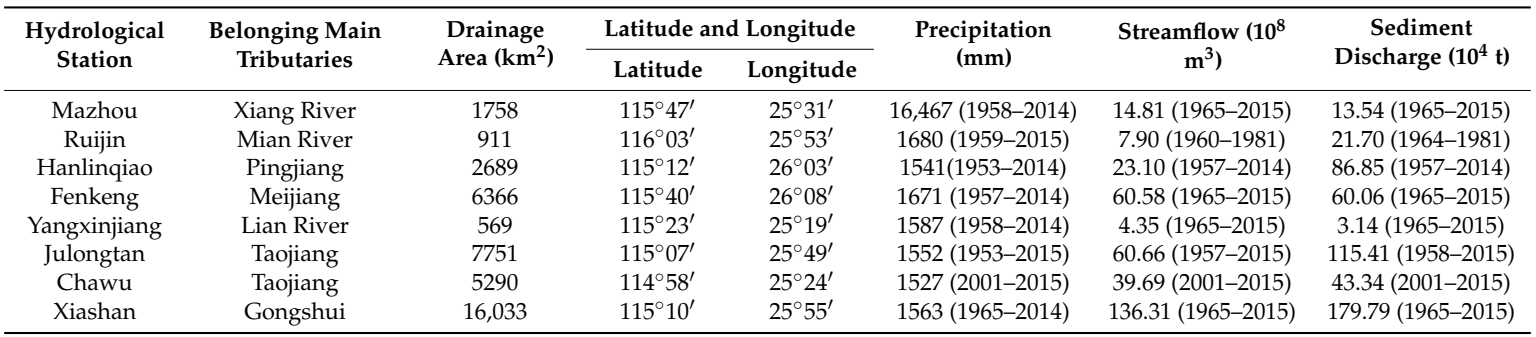




\section{Analysis Methods}

In this study, the inverse distance weighted interpolation method (IDW) was used to generate the spatially continuous distribution of raster data based on the interpolation of known measured precipitation data of counties within the research area. The values of average areal rainfall of the Gongshui River were then obtained, which reflect the situation of rainfall in this region objectively. Besides the point data interpolation method by GIS, the non-parametric Mann-Kendall trend test [24-27], Pettitt change-point analysis [28], and DMC method [20] were used to analyze the trends and change-points of precipitation, streamflow, and sediment discharge (Tables 2 and 3, Figures 2 and 3), and their driving forces (Figure 4, Tables 4 and 5) for their variations in the Gongshui River.

Table 2. The Mann-Kendall test of the annual, seasonal changes of precipitation, streamflow, and sediment discharge.

\begin{tabular}{|c|c|c|c|c|c|c|}
\hline \multicolumn{7}{|c|}{ Z Statistic with Significance Level } \\
\hline Stations & Variables & Annual & January-Mary & April-June & July-September & October-December \\
\hline \multirow{3}{*}{ Mazhou } & Precipitation & 0.49 & 0.60 & -0.89 & 0.78 & 0.03 \\
\hline & Streamflow & 0.80 & -0.37 & -0.80 & 1.34 * & 0.89 \\
\hline & Sediment & -0.02 & $-1.29 *$ & -0.95 & -0.09 & 0.42 \\
\hline \multirow{3}{*}{ Ruijin } & Precipitation & -0.59 & -0.01 & $-1.79 * *$ & 1.02 & -0.02 \\
\hline & Streamflow & 0.62 & 1.02 & 0.28 & $1.41 *$ & $1.64^{* *}$ \\
\hline & Sediment & $2.10^{* *}$ & 1.20 & $1.40 *$ & $3.10^{* *}$ & -0.98 \\
\hline \multirow{3}{*}{ Hanlinqiao } & Precipitation & -0.04 & 0.73 & $-1.46^{*}$ & 1.26 & -0.53 \\
\hline & Streamflow & 0.55 & 1.14 & $-1.72 * *$ & $2.40^{* *}$ & $1.82 * *$ \\
\hline & Sediment & $-5.00 * *$ & $-2.50 * *$ & $-5.00 * *$ & $-1.90 * *$ & -1.34 * \\
\hline \multirow{3}{*}{ Fenkeng } & Precipitation & 0.15 & 0.18 & $-1.99 * *$ & $2.68^{* *}$ & -0.01 \\
\hline & Streamflow & 0.18 & 0.39 & -0.81 & $2.20 * *$ & 0.77 \\
\hline & Sediment & $-1.96^{* *}$ & $-1.84^{* *}$ & $-2.40^{* *}$ & -0.31 & -0.47 \\
\hline \multirow{3}{*}{ Yangxinjiang } & Precipitation & 0.64 & 0.39 & -1.20 & 1.25 & -0.32 \\
\hline & Streamflow & -0.17 & -0.42 & -0.97 & 0.77 & -0.45 \\
\hline & Sediment & $4.05^{* *}$ & 0.34 & $2.45^{* *}$ & $2.85^{* *}$ & -0.15 \\
\hline \multirow{3}{*}{ Julongtan } & Precipitation & 0.21 & -0.28 & $-1.39 *$ & 0.97 & -1.12 \\
\hline & Streamflow & 0.05 & -0.22 & $-1.30 *$ & 0.88 & 0.09 \\
\hline & Sediment & $-2.00^{* *}$ & -0.91 & $-2.50 * *$ & -1.40 * & -1.25 \\
\hline \multirow{3}{*}{ Xiashan } & Precipitation & -0.65 & -0.6 & $-1.76^{* *}$ & 0.59 & -0.82 \\
\hline & Streamflow & 0.44 & 0.10 & -0.90 & $2.20^{* *}$ & 1.25 \\
\hline & Sediment & $-2.88^{* *}$ & $-2.40^{* *}$ & $-4.00 * *$ & -1.60 * & -0.69 \\
\hline \multirow{3}{*}{ Chawu } & Precipitation & 0.40 & -1.09 & 0.59 & -0.40 & $2.18^{* *}$ \\
\hline & Streamflow & -0.40 & -0.40 & 0.10 & -1.40 * & 0.69 \\
\hline & Sediment & $-2.00 * *$ & $-1.70^{* *}$ & $-2.00^{* *}$ & $-1.40^{*}$ & 0.20 \\
\hline
\end{tabular}

Notes: ${ }^{* *}$ significant at $p=0.05 ;{ }^{*}$ significant at $p=0.1$.

Table 3. The change-point analyses for annual precipitation, streamflow, and sediment discharge.

\begin{tabular}{|c|c|c|c|c|c|}
\hline Stations & Variables & Annual & Stations & Variables & Annual \\
\hline \multirow{3}{*}{ Mazhou } & Precipitation & - & \multirow{3}{*}{ Yangxinjiang } & Precipitation & - \\
\hline & Streamflow & - & & Streamflow & - \\
\hline & Sediment & - & & Sediment & $1994^{* *}$ \\
\hline \multirow{3}{*}{ Ruijin } & Precipitation & - & \multirow{3}{*}{ Julongtan } & Precipitation & - \\
\hline & Streamflow & - & & Streamflow & - \\
\hline & Sediment & $1972 * *$ & & Sediment & $2002^{* *}$ \\
\hline \multirow{3}{*}{ Hanlinqiao } & Precipitation & - & \multirow{3}{*}{ Xiashan } & Precipitation & - \\
\hline & Streamflow & - & & Streamflow & - \\
\hline & Sediment & $1985^{* *}$ & & Sediment & $1998^{* *}$ \\
\hline \multirow{3}{*}{ Fenkeng } & Precipitation & - & \multirow{3}{*}{ Chawu } & Precipitation & - \\
\hline & Streamflow & - & & Streamflow & - \\
\hline & Sediment & $1998^{* *}$ & & Sediment & $2007^{* *}$ \\
\hline
\end{tabular}

Notes: ${ }^{* *}$ significant at $p=0.05 ;$ - not significant. 

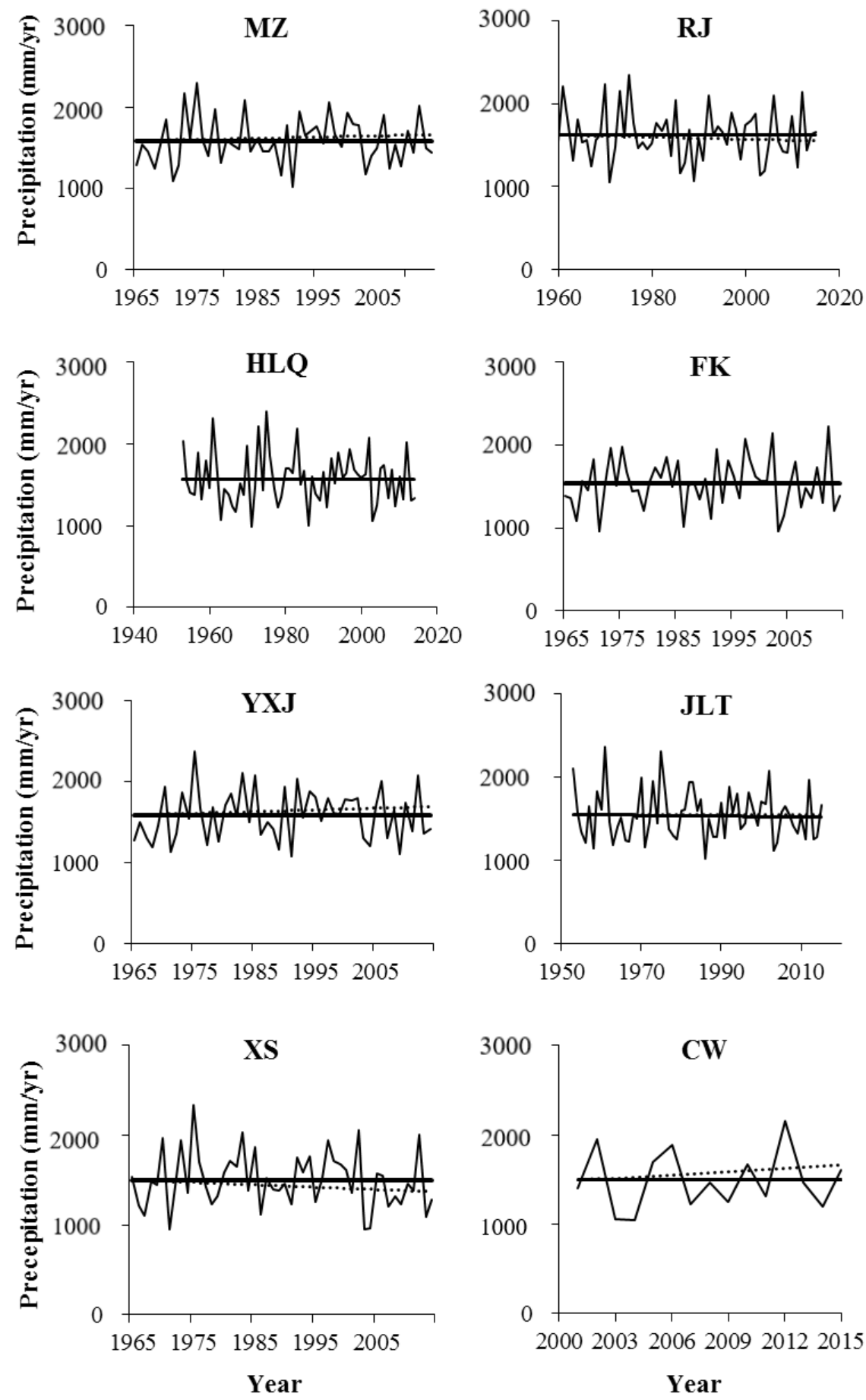

(a)

Figure 2. Cont. 

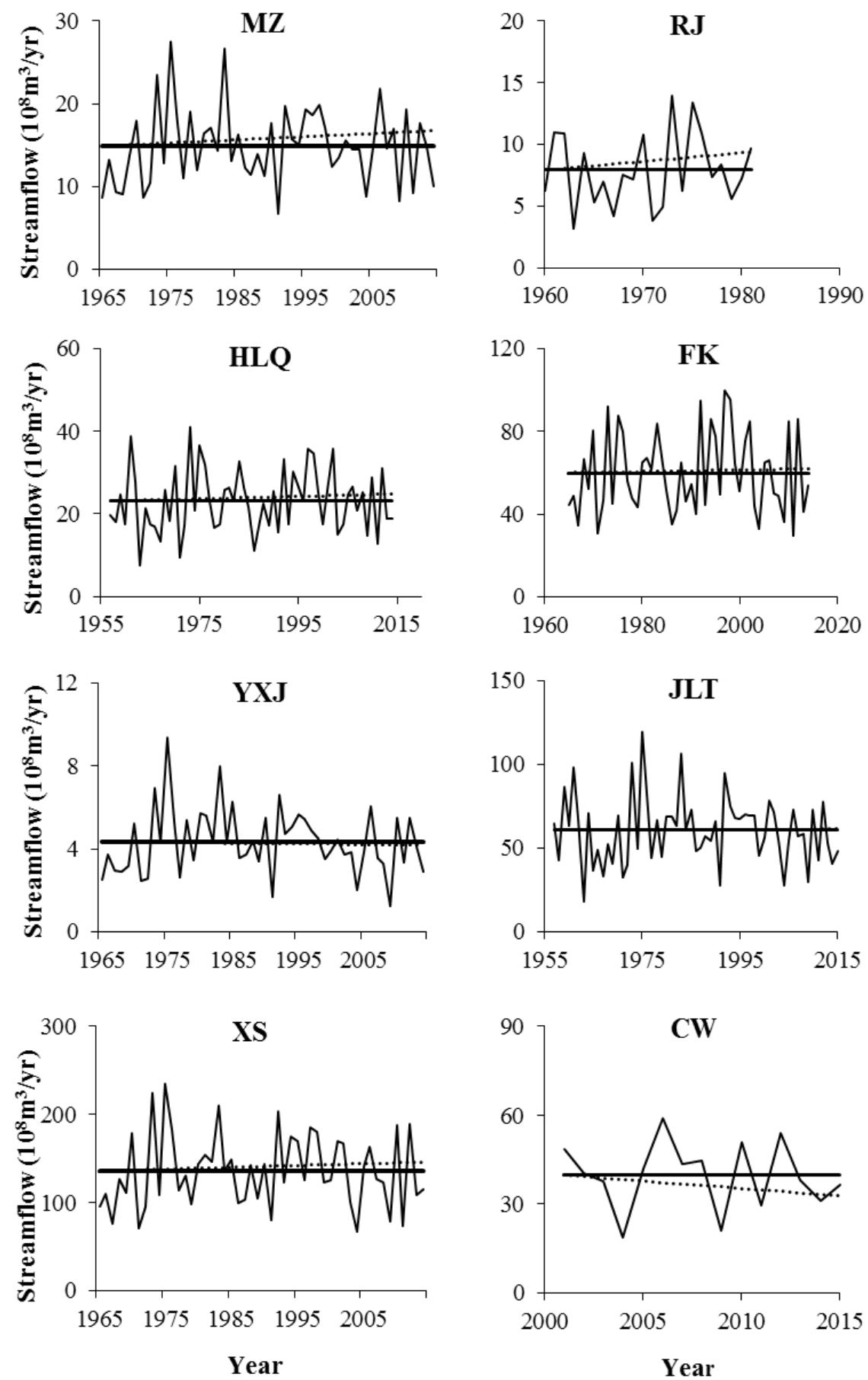

(b)

Figure 2. Cont. 

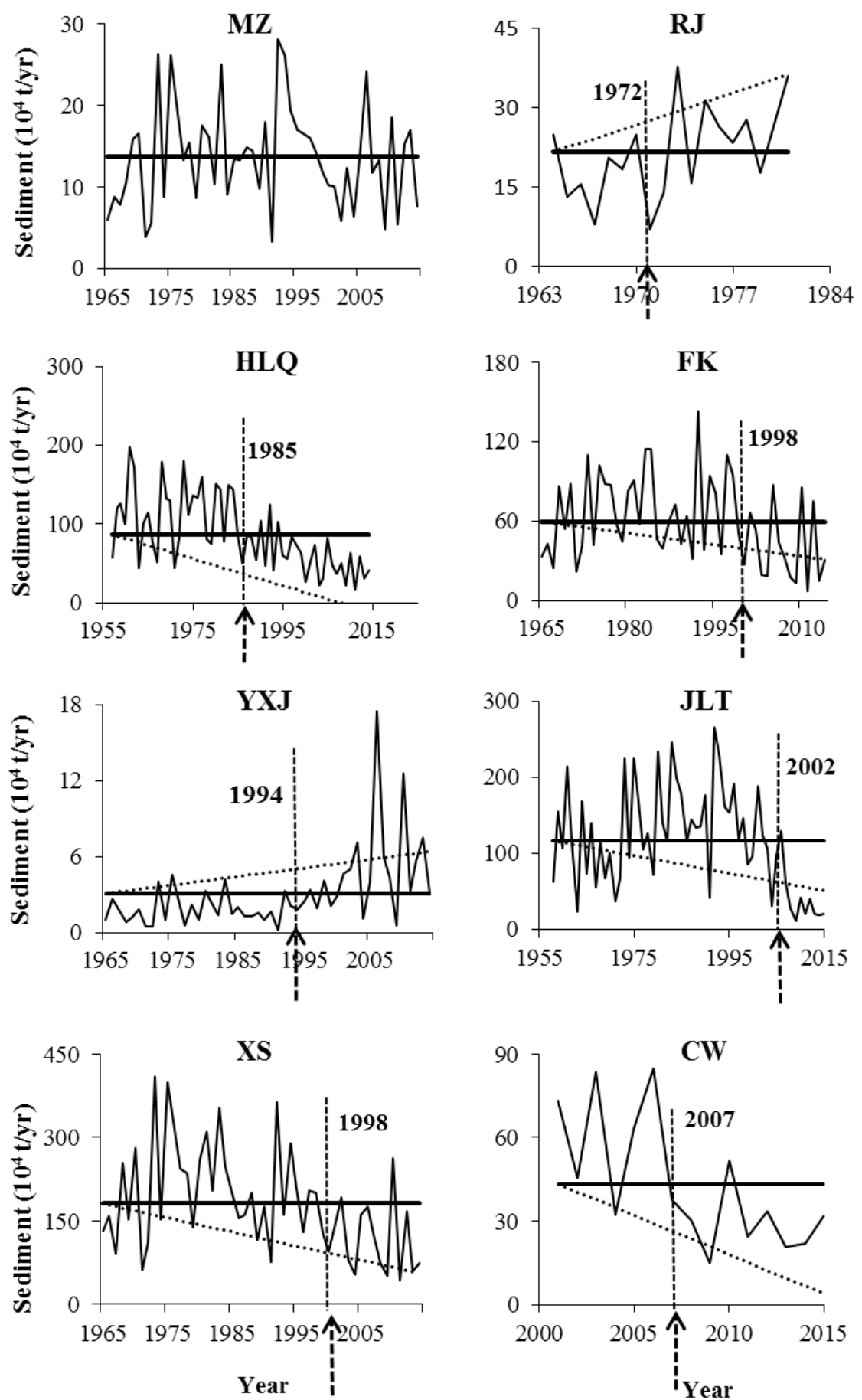

(c)

Figure 2. (a) Observed annual precipitation during 1950-2015 at eight hydrological stations on the Gongshui River of Ganjiang River basin. The horizontal solid and dashed lines are the mean values and trend lines, respectively. (b) Observed annual streamflow during 1950-2015 for the Gongshui River basin. (c) Observed annual sediment discharge of the Gongshui River of Ganjiang River basin. Note: MZ, RJ, FK, HLQ, YXJ, JLT, XS, and CW are abbreviations for Mazhou, Ruijin, Fenkeng, Hanlinqiao, Yangxinjiang, Julongtan, Xiashan, and Chawu, respectively. The horizontal solid and dashed lines are the mean values and trend lines, respectively, and the vertical dashed lines indicate the transition years. 

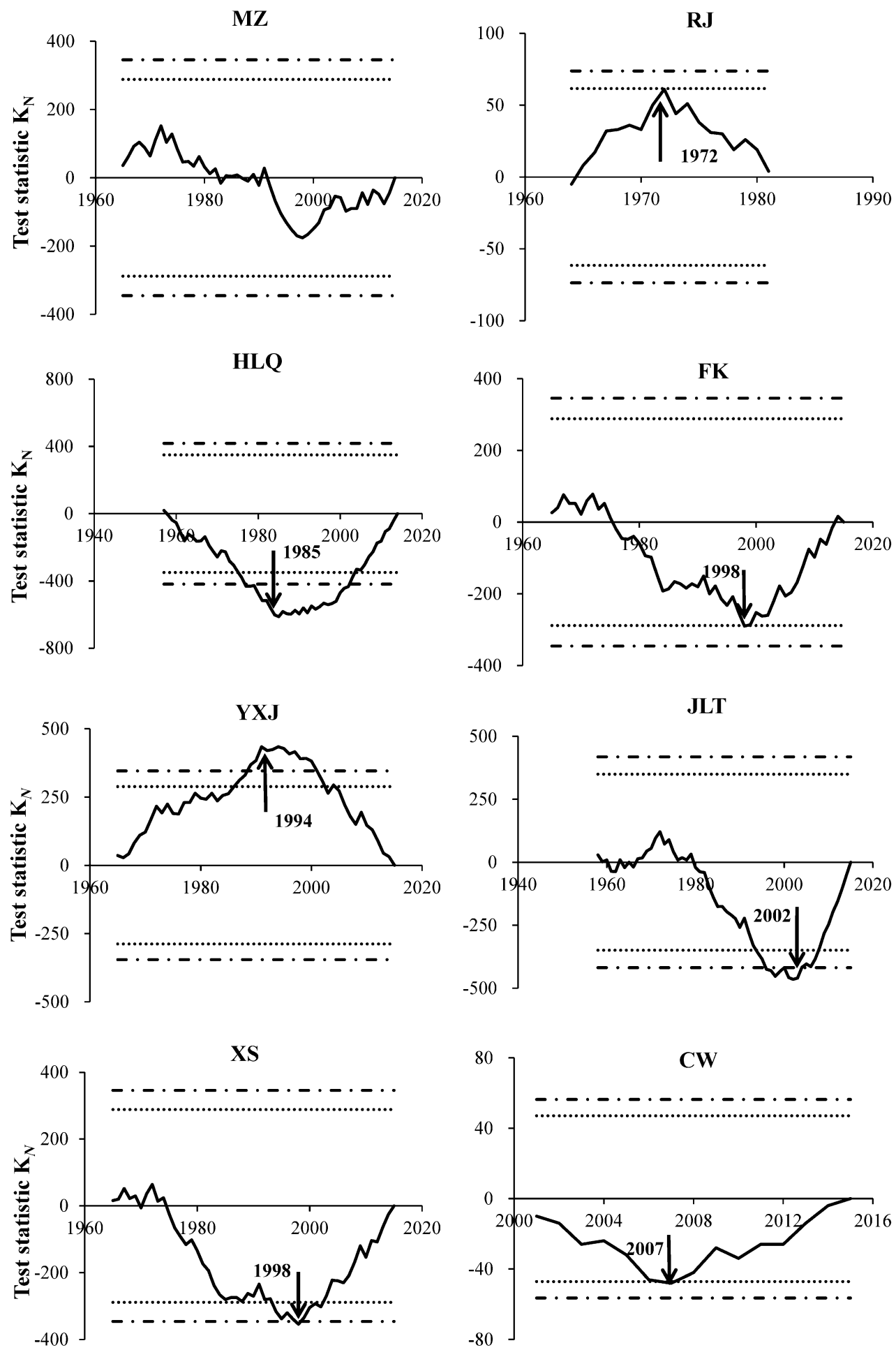

Figure 3. Pettitt's test KN statistic used for detecting a change point in annual sediment discharge of eight hydrological stations during 1950-2015 for the Gongshui River basin. The black arrow indicates the change-point year, and the horizontal lines represent the significance levels of $1 \%$ (dotted) and $5 \%$ (dash-dot), respectively. Note: MZ, RJ, FK, HLQ, YXJ, JLT, XS, and CW are abbreviations for Mazhou, Ruijin, Fenkeng, Hanlinqiao, Yangxinjiang, Julongtan, Xiashan, and Chawu, respectively. 

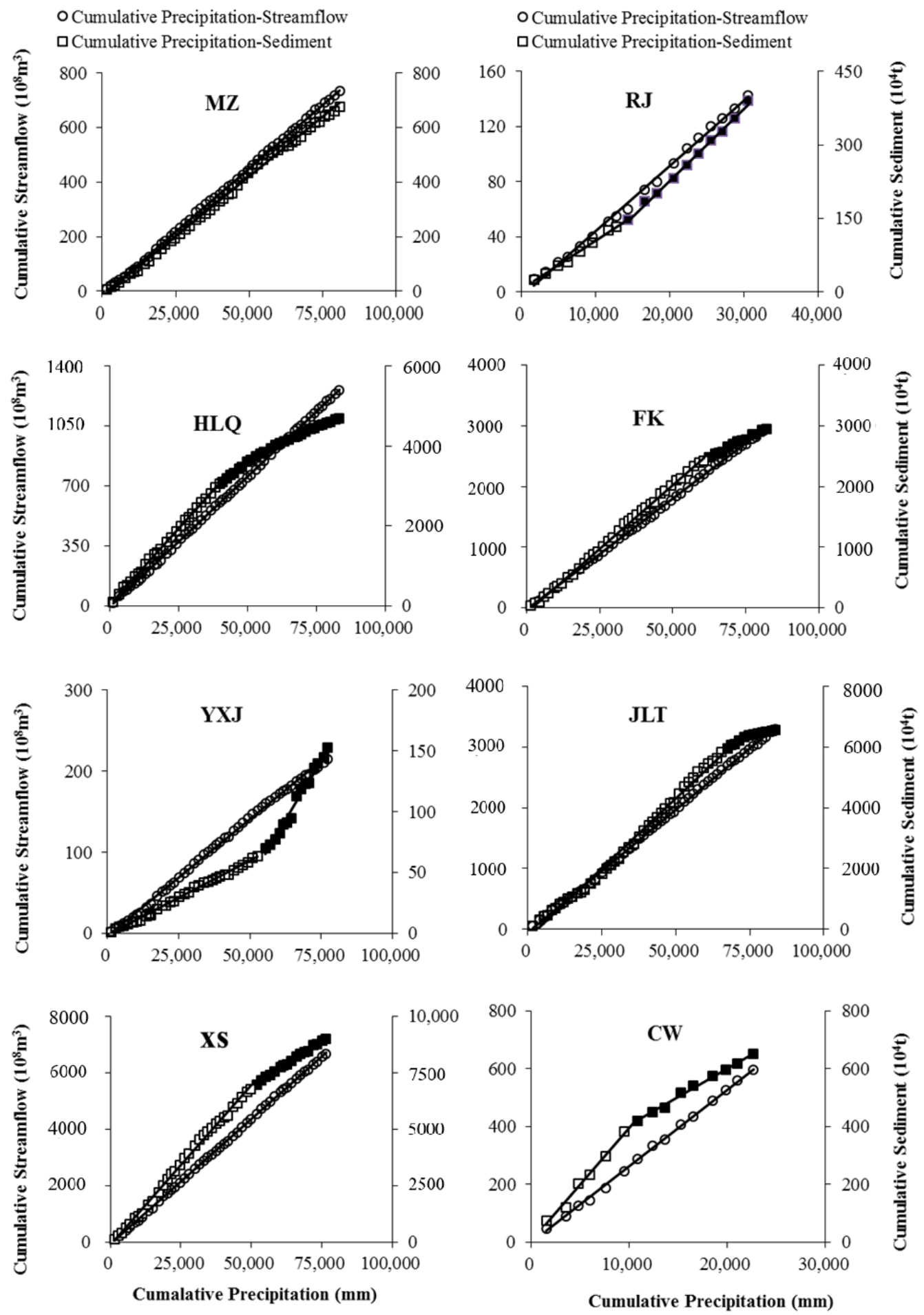

Figure 4. Double mass curves of precipitation-streamflow and precipitation-sediment of eight hydrological stations with sediment data on the Gongshui River basin. Note: MZ, RJ, FK, HLQ, YXJ, JLT, XS, and CW are abbreviations for Mazhou, Ruijin, Fenkeng, Hanlinqiao, Yangxinjiang, Julongtan, Xiashan, and Chawu, respectively. means the values of cumulative Precipitation-Sediment after the corresponding change point. 
Table 4. The cumulative sediment discharge calculated by the linear regression equations before the transition years.

\begin{tabular}{|c|c|c|c|c|c|}
\hline Station & Regression Equation & $S_{c}\left(10^{4} t\right)$ & $S_{o}\left(10^{4} t\right)$ & $S_{c}-S_{o}\left(10^{4} t\right)$ & $100 \times\left(S_{c}-S_{o}\right) / S_{c}(\%)$ \\
\hline Ruijin & $\begin{array}{c}\sum S_{r}=0.01 \sum P_{r}+4.4366 \\
\left(\mathrm{R}^{2}=0.994, N=8\right)\end{array}$ & 309.59 & 390.68 & -81.09 & -26.19 \\
\hline Hanlinqiao & $\begin{array}{c}\sum S_{h}=0.0767 \sum P_{h}-60.535 \\
\left(\mathrm{R}^{2}=0.999, N=28\right)\end{array}$ & 6807.63 & 5037.35 & 1770.28 & 26.00 \\
\hline Fenkeng & $\begin{array}{c}\sum S_{f}=0.0424 \sum \mathrm{P}_{f}-81.278 \\
\quad\left(\mathrm{R}^{2}=0.999, N=33\right)\end{array}$ & 3451.92 & 2985.90 & 466.02 & 13.50 \\
\hline Yangxinjiang & $\begin{array}{c}\sum S_{y}=0.0012 \sum P_{y}-1.0734 \\
\quad\left(R^{2}=0.995, N=29\right)\end{array}$ & 93.52 & 155.54 & -62.02 & -66.32 \\
\hline Julongtan & $\begin{array}{c}\sum S_{j}=0.0908 \sum \mathrm{P}_{j}-286.67 \\
\quad\left(\mathrm{R}^{2}=0.993, N=44\right)\end{array}$ & 7861.81 & 6809.01 & 1052.79 & 13.39 \\
\hline Xiashan & $\begin{array}{c}\sum S_{x}=0.1409 \sum P_{x}-132.38 \\
\quad\left(R^{2}=0.997, N=33\right)\end{array}$ & $10,652.38$ & 8978.91 & 1673.47 & 15.71 \\
\hline Chawu & $\begin{array}{c}\sum S_{c}=0.04 \sum \mathrm{P}_{c}-0.8699 \\
\left(\mathrm{R}^{2}=0.986, N=6\right)\end{array}$ & 905.51 & 650.15 & 255.36 & 28.20 \\
\hline
\end{tabular}

Notes: $S_{c}$, Cumulative sediment discharge; $S_{0}$, observed cumulative sediment discharge; $S_{c}-S_{0}$, reduction of cumulative sediment discharge after transition years for the Gongshui River ( $N=$ years, $p=$ precipitation).

Table 5. The impact of precipitation and human intervention on sediment discharge after the change-point year at seven stations on the Gongshui River ( $10^{4} \mathrm{t} /$ year).

\begin{tabular}{|c|c|c|c|c|c|c|c|c|c|}
\hline \multirow{2}{*}{ Stations } & \multirow{2}{*}{ Period } & \multirow{2}{*}{$R_{o}$} & \multirow{2}{*}{$R_{c}$} & \multicolumn{2}{|c|}{$\Delta R$} & \multicolumn{2}{|c|}{$\begin{array}{c}\text { Impact of } \\
\text { Precipitation }\end{array}$} & \multicolumn{2}{|c|}{$\begin{array}{l}\text { Impact of Human } \\
\text { Intervention }\end{array}$} \\
\hline & & & & $\begin{array}{l}\text { Amount } \\
\left(10^{4} t\right)\end{array}$ & $\begin{array}{l}\text { Percentage } \\
(\%)\end{array}$ & $\begin{array}{c}\text { Amount } \\
\left(10^{4} t\right)\end{array}$ & $\begin{array}{l}\text { Percentage } \\
(\%)\end{array}$ & $\begin{array}{c}\text { Amount } \\
\left(10^{4} t\right)\end{array}$ & $\begin{array}{l}\text { Percentage } \\
(\%)\end{array}$ \\
\hline \multirow{3}{*}{ Ruijin } & Before 1972 & 16.6 & 16.6 & & & & & & \\
\hline & 1972-1979 & 25.8 & 18.1 & -9.2 & -55.7 & -1.5 & 16.3 & -7.7 & 83.7 \\
\hline & 1980-1981 & 31.6 & 17.3 & -15.0 & -90.2 & -0.7 & 4.6 & -14.3 & 95.4 \\
\hline \multirow{5}{*}{ Hanlinqiao } & Before 1986 & 116.8 & 116.5 & & & & & & \\
\hline & 1986-1989 & 68.2 & 100.1 & 48.6 & 41.6 & 16.7 & 34.3 & 31.9 & 65.7 \\
\hline & 1990-1999 & 75.6 & 127.6 & 41.2 & 35.2 & -10.8 & -26.3 & 52.0 & 126.3 \\
\hline & 2000-2009 & 44.3 & 117.5 & 72.4 & 62.0 & -0.8 & -1.1 & 73.2 & 101.1 \\
\hline & 2010-2014 & 42.1 & 115.0 & 74.7 & 64.0 & 1.7 & 2.3 & 73.0 & 97.7 \\
\hline \multirow{4}{*}{ Fenkeng } & Before 1998 & 68.1 & 68.5 & & & & & & \\
\hline & 1999 & 50.8 & 71.7 & 17.3 & 25.4 & -3.6 & -20.9 & 20.9 & 120.9 \\
\hline & 2000-2009 & 38.0 & 68.7 & 30.0 & 44.1 & -0.7 & -2.3 & 30.7 & 102.3 \\
\hline & 2010-2014 & 42.9 & 69.5 & 25.2 & 37.0 & -1.4 & -5.7 & 26.6 & 105.7 \\
\hline \multirow{4}{*}{ Yangxinjiang } & Before 1994 & 1.9 & 1.9 & & & & & & \\
\hline & 1995-1999 & 2.8 & 1.9 & -1.0 & -51.6 & -0.0 & 4.2 & -0.9 & 95.8 \\
\hline & 2000-2009 & 5.3 & 1.8 & -3.5 & -187.1 & 0.0 & -0.9 & -3.5 & 100.9 \\
\hline & 2010-2014 & 6.4 & 1.9 & -4.6 & -244.6 & -0.1 & 1.5 & -4.5 & 98.5 \\
\hline \multirow{3}{*}{ Julongtan } & Before 2002 & 137.5 & 134.9 & & & & & & \\
\hline & 2003-2009 & 67.4 & 131.4 & 70.0 & 51.0 & 6.0 & 8.6 & 64.0 & 91.4 \\
\hline & 2010-2014 & 27.5 & 139.0 & 110 & 80.0 & -1.5 & -1.4 & 111.5 & 101.4 \\
\hline \multirow{4}{*}{ Xiashan } & Before 1998 & 210.9 & 217.5 & & & & & & \\
\hline & 1999 & 128.0 & 204.3 & 82.8 & 39.3 & 6.6 & 7.9 & 76.2 & 92.1 \\
\hline & 2000-2009 & 115.9 & 213.1 & 95.0 & 45.0 & -2.2 & -2.3 & 97.2 & 102.3 \\
\hline & 2010-2014 & 133.1 & 222.4 & 77.7 & 36.9 & -11.6 & -14.9 & 89.3 & 114.9 \\
\hline \multirow{3}{*}{ Chawu } & Before 2007 & 63.8 & 62.9 & & & & & & \\
\hline & 2007-2009 & 22.6 & 56.9 & 41.3 & 64.6 & 7.0 & 16.9 & 34.3 & 83.1 \\
\hline & 2010-2015 & 30.7 & 59.9 & 33.1 & 51.9 & 3.9 & 11.9 & 29.2 & 88.1 \\
\hline
\end{tabular}

Notes: $R_{c}$, Calculated sediment discharge; $R_{o}$, observed annual sediment discharge; $\Delta R$, reduction in observed sediment discharge compared with the period of before transition years for the Gongshui River $(N=$ years, $p=$ precipitation).

\subsection{Trend Test}

The rank-based, non-parametric Mann-Kendall statistical test has been widely used for trend detection due to its robustness for abnormally distributed data, especially in the time-series of 
hydro-climatic data $[13,20]$. For the time-series of a group of hydrological variables, $X_{i}(i=1,2$, $3, \ldots \ldots, n)$, the Mann-Kendall test statistic is defined as:

$$
S=\sum_{i=1}^{n-1} \sum_{j=i+1}^{n} \operatorname{sgn}\left(x_{j}-x_{i}\right)
$$

Here, $\operatorname{sgn}\left(x_{j}-x_{i}\right)=\left\{\begin{array}{cc}1 & x_{j}-x_{i}>0 \\ 0 & x_{j}-x_{i}=0 \\ -1 & x_{j}-x_{i}<0\end{array} ; n\right.$ is the sequence length, and when $n \geq 10$, the statistic $S$ obeys the normal distribution, and the equation of its mean $E(S)$ and variance $D(S)$ are $E(S)=0$, $D(S)=\frac{n(n-1)(2 n+5)}{18}$, respectively.

The $Z$ statistics obtained from the Mann-Kendall test can be used to judge whether or not the observed hydrological time-series variables (like streamflow) have been statistically significant. The normal distribution of test statistic $Z$ is calculated by the following formula:

$$
Z=\left\{\begin{array}{cc}
\frac{S-1}{\sigma} & S>0 \\
0 & S=0 \\
\frac{S+1}{\sigma} & S<0
\end{array}\right.
$$

Here, $\sigma=\sqrt{D(S)} \cdot Z_{(1-\alpha / 2)}$ is the critical value of the standard normal distribution with a probability exceeding $\alpha / 2$. The positive and negative values of $Z$ statistics denote increasing and decreasing trends, respectively. In this study, when the absolute value of $Z$ is greater than or equal to 1.28 and 1.64, it shows that the Mann-Kendall trend test is significant at the confidence levels $90 \%$ and $95 \%$, respectively (Table 2).

\subsection{Change-Point Analysis}

The non-parametric Pettitt method, with a statistical significance level of $5 \%$, was used to determine the transition year in which an abrupt change in the hydrological records of the Gongshui River may have occurred. Here, the test uses the Mann-Whiney statistic, $U_{t, T}$, to test whether two sample sets $x_{1}, x_{2}, \ldots \ldots, x_{t}$ and $x_{t+1}, \ldots \ldots, x_{T}$ are from the same population [28]. For successive sequences, the statistic, $U_{t, T}$, is given as:

$$
U_{t, T}=U_{t-1, T}+\sum_{j=1}^{T} \operatorname{sgn}\left(x_{t}-x_{j}\right) \text { Fort }=2, \ldots \ldots, T
$$

and

$$
\operatorname{sgn}\left(x_{t}-x_{j}\right)=\left\{\begin{array}{cc}
1 & x_{t}-x_{j}>0 \\
0 & x_{t}-x_{j}=0 \\
-1 & x_{t}-x_{j}<0
\end{array}\right.
$$

The test statistic is used to count the number of times that a member of the first sample exceeds a member of the second sample. The null hypothesis of the Pettitt method is the absence of a change-point. In this paper, the most significant change-point is identified by the test statistic $K_{T}$ and corresponding probability $(p)$, with their calculation formulas given as:

$$
\begin{gathered}
K_{T}=\max \left|U_{t, T}\right| \\
p=1-\exp \left(\frac{-6 K_{T}^{2}}{T^{3}+T^{2}}\right)
\end{gathered}
$$




\subsection{Double Mass Curve}

The double mass curve is currently the simplest, most direct, and most widely used method in the analysis of the consistency and long-term trend of hydro-meteorological elements [22,23]. Over the past decades, the effects of climate change and human activity on streamflow and sediment have been analyzed using the double mass curve method with good result $[13,14,29,30]$. In this study, the double mass curves along the linear regression lines were used to quantify the variations of streamflow and sediment discharge before and after the transition years.

If the slope of the regression lines after the change-point was greater than before the change-point, it means that the proportionalities between the cumulative streamflow or sediment discharge and precipitation were increased after the transition years, and vice versa. Furthermore, in order to estimate the relative changes of total streamflow or sediment discharge for the period after the transition years, equations fitted to the double curves before the transition years are extrapolated to the cumulative precipitation amounts. More details are given in Sections 4.3 and 4.4.

\section{Results and Analysis}

\subsection{Trends of Annual Precipitation, Streamflow and Sediment Discharge}

The results of the Mann-Kendall trend test of annual and seasonal precipitation, streamflow, and sediment discharge are summarized in Table 2. More than 1/3 (43 of 120) of the trend tests show significant changes. Fourteen of $120 \mathrm{Z}$ statistic values indicated significant upward trends, and 29 of 120 values indicated significant downward trends (Table 2). Among the 43 significant trends, 31 were significant at the $95 \%$ confidence level and the other 12 were significant at the $90 \%$ confidence level.

The variations of annual trend precipitation, streamflow, and sediment discharge are given in Figure 2. No significant trend $(p>0.05)$ was found in the variations of annual precipitation and streamflow. Precipitation had been fluctuating around the mean value $1500 \mathrm{~mm}$ (Figure 2a). Trend lines showed streamflow increasing over time at Mazhou, Ruijin, and Xiashan, while streamflow decreased with time at Chawu. The changes in magnitude of these variables at Ruijjin and Chawu were relatively large, but the differences were not significant at $p=0.01$ (Figure $2 b$ ). The variations in annual sediment discharge had a steep rise or drop (Figure 2c). Of the three sets of annual data analyzed (precipitation, streamflow, and sediment discharge), significant trends were only observed for sediment discharge. This finding agrees with the results of previous studies of trend changes of runoff and sediment in the Ganjian $[16,19,20]$. Moreover, the Mann-Kendall trend test for annual sediment discharge at seven of the eight hydrological stations (all except Mazhou) indicated a significant change $(p=0.95)$ (Table 2). The results obtained at only two (Ruijin and Yangxinjiang) of seven stations indicated significant upward trends. The data collected in the other five stations all showed significant downward trends. The data for sediment discharge at the Ruijin station came from the 1964-1981 time period. This period was before the first national key regulation engineering program institute to control soil erosion.

In the analysis of precipitation, streamflow, and sediment discharge by season, 36 of the 96 records show a clear trend. Specifically, in the seasonal period of January-March, there were five records with a significant trend (all for sediment discharge). During the April-June period, there were 14 records with a significant trend (streamflow 2, precipitation 5 and sediment discharge 7 ). For the July-September period, there were 13 records with a clear trend (precipitation 1, streamflow 6 and sediment discharge 6). Furthermore, for the October-December period, there were four records with a significant trend (precipitation 1, sediment discharge 1, streamflow 2) (Table 2). For the flood period (from April to September), 17 of 27 records ( 9 for sediment discharge, 5 for precipitation and 3 for streamflow) showed downward trends, and the other 10 records ( 5 for streamflow, 4 for sediment discharge and 1 for precipitation) showed upward trends. For the non-flood period (from October to March of the following year), the proportion of downward to upward trends was 2 to 1, 6 of 9 
records (all for sediment discharge) showed downward trends, and the other 3 records (precipitation 1 , streamflow 2) showed upward trends.

\subsection{The Change-Point Analysis}

The Pettitt's test was further used to detect the transition years when the significant changes began. The change-point analysis results of annual sediment discharge showed that transition years could be detected $(p=0.05)$ at all stations except Mazhou, while no change-point year could be detected for precipitation and streamflow $(p=0.1)$ at any station (Table 3).

Furthermore, $K_{N}$ statistics of Pettitt's test of sediment discharge at seven stations were significant, and different transition years were found (Table 3, Figure 3). At three stations (Ruijin, Fengkeng, and $\mathrm{Chawu}$ ), the transition year was determined at a significance level of 0.01 , while at four stations (Hanlinqiao, Yangxinjiang, Julongtan, and Xiashan), the transition year was determined at a significance level of 0.05. Specifically, the sediment discharge of Ruijin and Yangxinjiang stations significantly increased after their transition years of 1972 and 1994, respectively. Conversely, sediment discharge at Hanlinqiao, Fengkeng, Julongtan, Xiashan, and Chawu stations decreased significantly after their transition years of 1985, 1998, 2002, 1998, and 2007, respectively (Figures 2c and 3).

\subsection{Double Mass Curve of Precipitation-Streamflow and Precipitation-Sediment}

The streamflow and sediment discharge before and after the transition years were quantified with double mass curves (Figure 4) and the resultant linear regression lines (Table 4) from the eight hydrological stations. For the streamflow data from all of the stations, no clear breakpoint was found in the regression lines, verifying the results of Pettitt's test that detected no change-point year for precipitation and streamflow. However, for the sediment discharge observations, every regression line (except that of Mazhou station) had a clear breakpoint, consistent with the transition years identified by Pettitt's method. For Ruijin and Yangxinjiang stations, the slopes of the regression lines for sediment discharge were greater after the breakpoint than before (Figure 4). Because no significant precipitation change was found at any of the eight stations, the greater regression slope indicated that the ratio between sediment discharge and precipitation increased after the transition years, while the opposite was observed at Hanlinqiao, Fengkeng, Julongtan, Xiashan, and Chawu stations (Figure 4).

To estimate the proportional changes of total sediment discharge for the period after the transition years, equations fitted to the double curves before the transition years were extrapolated to the cumulative precipitation amounts (Table 4$)$. The extrapolated cumulative sediment discharge $\left(S_{c}\right)$ was based on the assumption that environmental conditions and human impacts during the first period remained unchanged during the second period (after the transition year). Compared with $S_{c}$, observed cumulative sediment $\left(S_{o}\right)$ was reduced by $26.0 \%, 13.5 \%, 13.4 \%, 15.7 \%$, and $28.2 \%$ at Hanlinqiao, Fengkeng, Julongtan, Xiashan, and Chawu stations, and increased by $26.2 \%$ and $66.3 \%$ at Ruijin and Yangxinjiang stations, respectively.

In general, precipitation variation and human activity are the two main factors affecting watershed streamflow and sediment delivery [31-33]. In this study, precipitation did not show any significant change in the annual trend since the beginning year for each station, according to the Mann-Kendall and Pettitt test. Consequently, human activities such as constructing water storage projects, afforestation or deforestation, and various land use changes, are the most plausible factors responsible for sediment discharge changes in the Gongshui River Basin since the 1980s, especially after 1983.

\subsection{Impacts of Precipitation and Human Interference}

The annual sediment discharge for the period after the transition years could be calculated by the regression equations established from the double mass curve of precipitation-sediment before the transition years [13]. The difference between the calculated values in different periods is caused by precipitation variation, while the difference between calculated and measured values in the same period is the impact of human intervention. The detailed results in this study are given in Table 5 . 
Many studies have documented that compared with the precipitation variation, the role of human activity plays a much more important role in the streamflow and sediment discharge reduction at the Poyang Lake River basin, especially at the decadal scale [8,11,15-21], which agrees with the study of Wang et al. [34]. Regarding the increase in sediment discharge at Ruijin station, the impact of human activities showed an increasing trend from $83.7 \%$ in the 1970 s to $95.4 \%$ in the $1980 \mathrm{~s}$, which is significantly stronger than the contribution of precipitation (from $4.6 \%$ to $16.3 \%$ ). A similar result was found at Yangxinjiang station. Furthermore, human activity was also the dominant factor in the sediment discharge decline after the transition years at five other hydrological stations. During some periods, the contribution rate of human activities was more than $100 \%$ (e.g., $126.3 \%$ in the 1990 s at Hanlinqiao station), which was caused by the increased precipitation and decreased sediment discharge (Table 5).

\subsection{Impacts of Human Intervention in Sediment Discharge Variation}

Domestic and overseas studies have shown that the key drivers of increased sediment loads include land clearance for agriculture, logging activity, and mining. While anthropogenic causes involving programs for soil conservation, land use change, and dam construction control the long-term decrease in sediment discharge [22,31-36]. Some previous relevant studies have also reported on human activities that increased vegetation coverage or reduced soil erosion (from 1983-1997). Additionally, the construction of large- and medium-sized reservoirs in recent decades may have played an important role in sediment discharge reduction in the Gongshui River Basin $[15,19]$. The results of the current study suggest the following.

Firstly, two national key regulation engineering programs dealing with water and soil erosion are plausibly the most important influencing factors. The Gongshui River, located upstream of the Ganjiang of Jiangxi province, flows through a typical hilly mountain area with heavy water and soil erosion. In the last 80-90 years of the previous century, two national programs dealing with water and soil erosion were carried out, resulting in the comprehensive management and development of mountain, water, field, forest, and grass resources and roads in this area. The first period was 1983-1992 in Xingguo, and the second period was 1993-1997 in both Xingguo and five other cities (Yudu, Ningdu, Ruijin, Huichang, and Shicheng) [15]. The effects of soil erosion control in these two periods can be plainly seen in the rate of reduction in soil erosion shown in Table 6. The total area of soil erosion and the level of erosion intensity in both the 1983-1992 period and the 1992-1997 period clearly demonstrate the positive effects of soil erosion control in first period (Intense and Severe erosion were reduced $96.8 \%$ and $99 \%$, respectively) in Xingguo county. These reductions in erosion are much greater than what was observed during the second period (Intense and Severe erosion were reduced only $23.6 \%$ and 24.8\%). The transition year for the hydrological station Hanlinqiao occurred in 1985, during the first period, located in Xingguo city of Pingjiang branch (Table 6). For both Julongtan and Chawu stations (located in Taojiang branch in Ganxian County), water and soil conservation measures occurred later, such that the transition years for those two stations occurred in 2002 and 2007, respectively (Table 1, Figure 3). The land-use changes in the six counties of the Gongshui River Basin from 1992 to 1997 are shown in Table 7. Among the six land use types, the area of farmland, water, and construction land remained essentially unchanged from 1992 to 1997. The main changes occurred in forestland, grassland, and unused land. The forest and grass coverage of all seven cities was increasing, with a corresponding decrease in unused land. With the exception of Xingguo and Shicheng, the forest coverage rate of the cities increased by more than $10 \%$ within five years; for example, at Yudu, forest coverage increased from $53.4 \%$ in 1992 to $66.1 \%$ in 1997. 
Table 6. The governance of water and soil erosion in the six counties of the Gongshui River Basin.

\begin{tabular}{|c|c|c|c|c|c|c|}
\hline Cities & Years & $\begin{array}{l}\text { Total Area of Soil } \\
\text { Erosion }\left(\mathbf{k m}^{2}\right)\end{array}$ & $\begin{array}{l}\text { Light } \\
\text { Erosion }\end{array}$ & $\begin{array}{l}\text { Moderate } \\
\text { Erosion }\end{array}$ & $\begin{array}{l}\text { Intense } \\
\text { Erosion }\end{array}$ & $\begin{array}{l}\text { Severe } \\
\text { Erosion }\end{array}$ \\
\hline \multirow{5}{*}{ Xingguo } & 1983 & 1899.07 & 1453.65 & 884.69 & 4700.43 & 157 \\
\hline & 1992 & 813.39 & 445.33 & 216.13 & 150.36 & 1.57 \\
\hline & 1997 & 463.33 & 214.67 & 132.63 & 114.85 & 1.18 \\
\hline & $\begin{array}{l}\text { Reduction rate } \\
\text { (1992-1983) }\end{array}$ & $57.17 \%$ & $69.36 \%$ & $75.57 \%$ & $96.80 \%$ & $99.00 \%$ \\
\hline & $\begin{array}{l}\text { Reduction rate } \\
(1997-1992)\end{array}$ & $43.04 \%$ & $51.80 \%$ & $38.63 \%$ & $23.62 \%$ & $24.84 \%$ \\
\hline \multirow{3}{*}{ Yudu } & 1992 & 1063.73 & 383.33 & 410.8 & 185.6 & 84 \\
\hline & 1997 & 777.5 & 337.56 & 303.97 & 84.86 & 51.11 \\
\hline & Reduction rate & $26.91 \%$ & $11.94 \%$ & $26.01 \%$ & $54.28 \%$ & $39.15 \%$ \\
\hline \multirow{3}{*}{ Ruijin } & 1992 & 745.2 & 383.41 & 174.45 & 187.34 & - \\
\hline & 1997 & 577.33 & 297.67 & 133.12 & 146.54 & - \\
\hline & Reduction rate & $22.53 \%$ & $22.36 \%$ & $23.69 \%$ & $21.78 \%$ & - \\
\hline \multirow{3}{*}{ Huichang } & 1992 & 664.52 & 297.06 & 155 & 212.46 & - \\
\hline & 1997 & 565.59 & 262.25 & 110.09 & 193.25 & - \\
\hline & Reduction rate & $14.89 \%$ & $11.72 \%$ & $28.97 \%$ & $9.04 \%$ & - \\
\hline \multirow{3}{*}{ Ningdu } & 1992 & 1025 & 647 & 137 & 241 & - \\
\hline & 1997 & 831 & 542 & 94 & 195 & - \\
\hline & Reduction rate & $18.93 \%$ & $16.23 \%$ & $31.39 \%$ & $19.09 \%$ & - \\
\hline \multirow{3}{*}{ Shicheng } & 1992 & 502.13 & 242.73 & 167.93 & 91.47 & - \\
\hline & 1997 & 405.27 & 198.13 & 146.22 & 60.92 & - \\
\hline & Reduction rate & $19.29 \%$ & $18.37 \%$ & $12.93 \%$ & $33.40 \%$ & - \\
\hline
\end{tabular}

Notes: Information comes from data compilation $<$ Water and soil conservation project in the seven major basins of China: document literature on the key management of the Gongshui River Basin in Jiangxi province>.

Table 7. Land-use classification (\% of total area) in the six counties of Gongshui River Basin in 1992 and 1997.

\begin{tabular}{|c|c|c|c|c|c|c|c|c|}
\hline Cities & $\begin{array}{l}\text { Project Area } \\
\left(\mathrm{km}^{2}\right)\end{array}$ & Years & Farmland & Forestland & Grassland & Water & $\begin{array}{l}\text { Construction } \\
\text { Land }\end{array}$ & $\begin{array}{c}\text { Unused } \\
\text { Land }\end{array}$ \\
\hline \multirow{2}{*}{ Xingguo } & \multirow{2}{*}{184.74} & 1992 & 11.4 & 61.7 & 1.4 & 8.5 & 12.0 & 5.1 \\
\hline & & 1997 & 11.3 & 64.6 & 1.7 & 8.5 & 12.1 & 1.9 \\
\hline \multirow{2}{*}{ Yudu } & \multirow{2}{*}{112.27} & 1992 & 12.1 & 53.4 & 0.2 & 5.9 & 8.8 & 19.6 \\
\hline & & 1997 & 12.3 & 66.1 & 2.4 & 5.5 & 9.0 & 4.7 \\
\hline \multirow{2}{*}{ Ruijin } & \multirow{2}{*}{57.98} & 1992 & 14.9 & 50.9 & 0.0 & 7.4 & 6.6 & 20.2 \\
\hline & & 1997 & 14.9 & 61.4 & 2.5 & 7.4 & 6.6 & 7.1 \\
\hline \multirow{2}{*}{ Huichang } & \multirow{2}{*}{55.08} & 1992 & 17.5 & 43.1 & 1.2 & 5.5 & 11.8 & 16.4 \\
\hline & & 1997 & 18.5 & 60.6 & 2.8 & 5.5 & 11.8 & 0.8 \\
\hline \multirow{2}{*}{ Ningdu } & \multirow{2}{*}{43.43} & 1992 & 13.2 & 58.3 & 0.0 & 3.8 & 6.8 & 5.6 \\
\hline & & 1997 & 13.2 & 73.8 & 2.3 & 3.8 & 6.8 & 0.1 \\
\hline \multirow{2}{*}{ Shicheng } & \multirow{2}{*}{188.13} & 1992 & 2.9 & 87.0 & 0.1 & 1.4 & 1.3 & 1.5 \\
\hline & & 1997 & 2.9 & 93.7 & 0.6 & 1.4 & 1.4 & 0.0 \\
\hline \multirow{2}{*}{ Gongshui } & \multirow{2}{*}{503.61} & 1992 & 12.7 & 57.1 & 0.7 & 6.7 & 9.5 & 11.4 \\
\hline & & 1997 & 12.9 & 66.1 & 2.2 & 6.6 & 9.6 & 2.7 \\
\hline
\end{tabular}

Notes: Information comes from data compilation $<$ Water and soil conservation project in the seven major basins of China: document literature on the key management of the Gongshui River Basin in Jiangxi province>.

Secondly, the impact of the construction of large and medium reservoirs on sediment discharge is another important factor [15]. The construction time was divided into three periods: before 1980, 1981-2000, after 2000. In the past 60 years, 33 large and medium reservoirs had been built $(13,8$, and 12 in the three periods, respectively). During the period "before 1980", the total water-collecting area was $2258.5 \mathrm{~km}^{2}$, mainly distributed in Taojiang, Pingjiang, Meijiang, and Mian River basins. During the 1981-2000 period, the total water-collecting area was $3077 \mathrm{~km}^{2}$, mainly distributed in Lian River, Taojiang, Meijiang, and Xiang River basins. After 2000, the total water-collecting area was very large, more than $50,666 \mathrm{~km}^{2}$, mainly distributed in Xiang River, Meijiang, and Taojiang (Table 8). For the Ruijing station, the sediment discharge data was collected in the 1964-1981 period, which was before the second national governance period when few reservoirs were being constructed. In that 
period, human-caused disturbances such as deforestation, steel production, mining, and engineering construction and unreasonable land use patterns caused serious vegetation destruction and soil erosion. Consequently, after the change-point year of 1972, the sediment discharge increased (Figures 2c and 4). For Yudu, the effect of soil erosion control during the second national governance was much smaller than that of the two national water-and-soil conservation measures at Xingguo (Table 6). Furthermore, the total water-collecting area of reservoirs constructed was much smaller than at Fenkeng and Xiashan before 2000, such that the transition years for these two hydrological stations both occurred in 1998 (after the end of governance) (Figure 3, Table 8).

Table 8. The construction of large- and medium-sized reservoirs in the past 60 years.

\begin{tabular}{|c|c|c|c|c|c|c|c|c|}
\hline \multirow{2}{*}{$\begin{array}{l}\text { Hydrological } \\
\text { Station }\end{array}$} & \multirow{2}{*}{ County } & \multicolumn{2}{|c|}{ Before 1980} & \multicolumn{2}{|c|}{ 1981-2000 } & \multicolumn{3}{|c|}{ After 2000 (Especially around 2010) } \\
\hline & & $\begin{array}{l}\text { Number of } \\
\text { Reservoirs }\end{array}$ & $\begin{array}{c}\text { Drainage } \\
\text { Area }\left(\mathbf{k m}^{2}\right)\end{array}$ & Number & $\begin{array}{c}\text { Drainage } \\
\text { Area }\left(\mathbf{k m}^{2}\right)\end{array}$ & Number & Drain & Area \\
\hline Mazhou & Huichang & - & - & 1 & 164 & 5 & & \\
\hline Ruijin & Ruijin & 2 & 280 & - & - & - & & \\
\hline Hanlinqiao & Xingguo & 3 & 994.9 & - & - & - & & \\
\hline Fenkeng & Yudu & 1 & 412 & 3 & 154.3 & 2 & & \\
\hline Yangxinjiang & Anyuan & - & - & 2 & 2257 & & & \\
\hline Xiashan & Yudu & & & & & 2 & & $x$ \\
\hline $\begin{array}{l}\text { Chawu } \\
\text { Julongtan }\end{array}$ & Ganxian & 7 & 571.6 & 2 & 501.7 & 3 & 14,071 & - \\
\hline \multicolumn{2}{|c|}{ Grand total } & 13 & 2258.5 & 8 & 3077 & 12 & 50,6 & \\
\hline
\end{tabular}

Notes: -/X: Indicates no data and inexact data, respectively. Table's data information comes from the water conservancy census of Jiangxi Province in 2010.

Two hydrological stations (Mazhou and Yangxinjiang) showed different results. Although five large-sized reservoirs had been built for Mazhou around 2010, the water-soil erosion control and reservoir construction were not adequate before 2000, and the sediment discharge reduction is not significant at the present time. While for Yangxinjiang station, the sediment discharge increased even though two reservoirs were constructed in the 1981-2000 period that encompassed a relatively large drainage are of $2257 \mathrm{~km}^{2}$. This increase may be caused by land-use change due to unknown human activities, such as man-made destruction. All of these cases show that the types and times of human interference that are implemented closely correspond to the transition years of sediment discharge identified by the Pettitt change-point analysis.

\section{Conclusions}

Precipitation, streamflow, and sediment discharge in the Gongshui River during 1957-2015 were analyzed by the Mann-Kendall trend test, Pettitt change-point analysis, and double mass curve. There were significant trends $(p<0.05)$ for annual sediment discharge at all hydrological stations except Mazhou station, and no significant trends $(p>0.05)$ for either precipitation or streamflow. When analyzed by three-month quarters, significant upward and downward trends could be found in the three measured quantities. Significant transition years were found in annual sediment discharge at most stations, while no change-point existed in the precipitation and streamflow data at any of the stations. Double mass curves indicated that human activity was the most plausible factor responsible for sediment discharge changes in the Gongshui River basin since the 1980s. Compared with the period before the transition years, measured cumulative sediment discharge decreased from $13.4 \%$ to $28.2 \%$ at Hanlinqiao, Fengkeng, Julongtan, Xiashan, and Chawu stations, and increased by $26.2 \%$ and $66.3 \%$ at Ruijin and Yangxinjiang, respectively. The average human activities contribution rates were more than $85 \%$ for sediment discharge increases or decreases, which were significantly larger than the precipitation contribution rates (lower than $15 \%$ ).

Extensive conservation measures like vegetation rehabilitation, and dam and reservoir construction altered the natural regimes of sediment discharge and led to an abrupt decline in 1985 at Hanlinqiao, in 1998 at Fenkeng and Xiashan, in 2002 at Julongtan, and in 2007 at Chawu. The overall results showed that human activities, including water-and-soil conservation or destruction measures 
(such as deforestation) and the construction of large- and medium-sized reservoirs played major roles in the significant changes in sediment discharge of the Gongshui River during the last few decades. More importantly, the reduced sediment discharge will directly impact sediment deposition of the river channel, so as to exert a positive influence on the conservation of ecological environment and flood mitigation in the Gongshui River basin, and further impact the geomorphological evolution of the river channel of the Gangiiang, Poyang Lake, and the middle and lower Yangtze River basin.

Author Contributions: X.-M.M., J.-M.H. contributed to the conception of the study. Q.Y., J.-M.H., X.-F.N. acquired data; P.G., -K.T.L. contributed significantly to analysis and manuscript preparation; L.-P.G. performed the data analyses and wrote the manuscript; X.-L.C., X.-F.N. helped revised the manuscript.

Funding: This research was jointly supported by National Natural Science Foundation of China (Nos. 41461058, 51769008), and Key Research and Development Project (No. 20161BBH80072), Postdoctoral Scientific Financed Project (No. 2016KY22), Scientific Major Project of Water Conservancy (No. KT201716) in Jiangxi Province.

Acknowledgments: We are very grateful to Tian-Duo Wang and anonymous reviewers for their critical reviews of this paper.

Conflicts of Interest: The authors declare no conflict of interest.

\section{References}

1. Zhang, W.; Yan, Y.; Zheng, J.; Wu, H. Interannual tidal range trend in Pearl River delta. Adv. Water Sci. 2010, 21, 78-83.

2. Dey, P.; Mishra, A. Separating the impacts of climate change and human activities on streamflow: A review of methodologies and critical assumptions. J. Hydrol. 2017, 548, 278-290. [CrossRef]

3. Li, T.; Wang, S.; Liu, Y.; Fu, B.; Zhao, W. Driving forces and their contribution to the recent decrease in sediment flux to ocean of major rivers in China. Sci. Total Environ. 2018, 634, 534-541. [CrossRef] [PubMed]

4. Zhao, G.; Mu, X.; Jiao, J.; Gao, P.; Sun, W.; Li, E.; Wei, Y.; Huang, J. Assessing response of sediment load variation to climate change and human activities with six different approaches. Sci. Total Environ. 2018, 639, 773-784. [CrossRef] [PubMed]

5. Wu, J.; Miao, C.; Zhang, X.; Yang, T.; Duan, Q. Detecting the quantitative hydrological response to changes in climate and human activities. Sci. Total Environ. 2017, 586, 328-337. [CrossRef] [PubMed]

6. Zhang, Q.; Xu, C.; Singh, V.P.; Yang, T.; Det, T.V.; Universitet, U.; Sektionen, G.; Geovetenskaper, I.F.R.; Luft, V.O.L.R. Multiscale variability of sediment load and streamflow of the lower Yangtze River basin: Possible causes and implications. J. Hydrol. 2009, 368, 96-104. [CrossRef]

7. Guo, L.; Su, N.; Zhu, C.; He, Q. How have the river discharges and sediment loads changed in the Changjiang River basin downstream of the Three Gorges Dam? J. Hydrol. 2018, 560, 259-274. [CrossRef]

8. Zhang, Q.; Liu, J.Y.; Singh, V.P.; Gu, X.H.; Chen, X.H. Evaluation of impacts of climate change and human activities on streamflow in the Poyang Lake basin, China. Hydrol. Process. 2016, 30, 2562-2576. [CrossRef]

9. Jiang, C.; Zhang, L.B.; Tang, Z.P. Multi-temporal scale changes of streamflow and sediment discharge in the headwaters of Yellow River and Yangtze River on the Tibetan Plateau, China. Ecol. Eng. 2017, 102, 240-254. [CrossRef]

10. Zhang, Q.; Xu, C.Y.; Becker, S.; Jiang, T. Sediment and runoff changes in the Yangtze River basin during past 50 years. J. Hydrol. 2006, 331, 511-523. [CrossRef]

11. Gao, J.H.; Jia, J.J.; Kettner, A.J.; Xing, F.; Wang, Y.P.; Xu, X.N.; Yang, Y.; Zou, X.Q.; Gao, S.; Qi, S.H.; et al. Changes in water and sediment exchange between the Changjiang River and Poyang Lake under natural and anthropogenic conditions, China. Sci. Total Environ. 2014, 481, 542-553. [CrossRef] [PubMed]

12. Gao, P.; Zhang, X.; Mu, X.; Wang, F.; Li, R.; Zhang, X. Trend and change-point analyses of streamflow and sediment discharge in the Yellow River during 1950-2005. Hydrol. Sci. J. 2010, 55, 275-285. [CrossRef]

13. Gao, P.; Mu, X.M.; Wang, F.; Li, R. Changes in streamflow and sediment discharge and the response to human activities in the middle reaches of the Yellow River. Hydrol. Earth Syst. Sci. 2011, 15, 1-10. [CrossRef]

14. Mu, X.M.; Zhang, X.Q.; Shao, H.B.; Gao, P.; Wang, F.; Jiao, J.Y.; Zhu, J.L. Dynamic changes of sediment discharge and the influencing factors in the Yellow River, China, for the recent 90 years. Clean Soil Air Water 2011, 40, 303-309. [CrossRef] 
15. Sun, P.; Zhang, Q.; Chen, X.H.; Chen, Y.Q. Spatio-temporal patterns of sediment and runoff changes in the Poyang Lake Basin and underlying causes. Acta Geogr. Sin. 2010, 65, 828-840.

16. Guo, H.; Hu, Q.; Jiang, T. Annual and seasonal streamflow responses to climate and land-cover changes in the Poyang Lake basin, China. J. Hydrol. 2008, 355, 106-122. [CrossRef]

17. Zhao, G.; Hörmann, G.; Fohrer, N.; Zhang, Z.; Zhai, J. Streamflow trends and climate variability impacts in Poyang Lake Basin, China. Water Resour. Manag. 2010, 24, 689-706. [CrossRef]

18. Xu, X.N.; Gao, J.H.; Jia, J.J.; Albert, J.K.; Xing, F.; Wang, Y.; Qi, S.H.; Liao, F.Q. The quantitative estimation of sediment load changes entering Poyang Lake Basin induced by climate change and anthropogenic impacts. Geogr. Res. 2015, 34, 838-850.

19. Zheng, H.J.; Fang, S.W.; Yang, J.; Xie, S.H.; Chen, X.A. Analysis on evolution characteristics and impacting factors of annual runoff and sediment in the Ganjiang River during 1970-2009. J. Soil Water Conserv. 2012, $26,28-32$.

20. Gao, P.; Mu, X.M.; Wang, F. An analysis of streamflow and sediment discharge in Ganjiang River trend and driving force. China Rural Water Hydropower 2012, 1, 56-59, 63.

21. Gu, C.J.; Mu, X.M.; Gao, P.; Zhao, G.J.; Sun, W.Y.; Li, P.F. Effects of climate change and human activities on runoff and sediment inputs of the largest freshwater lake in China, Poyang Lake. Hydrol. Sci. J. 2017, 62, 2313-2330. [CrossRef]

22. Siakeu, J.; Oguchi, T.; Aoki, T.; Esaki, Y.; Jarvie, H.P. Change in riverine suspended sediment concentration in central Japan in response to late 20th century human activities. Catena 2004, 55, 231-254. [CrossRef]

23. Soil and Water Conservation Committee Office of Jiangxi Province. Water and Soil Conservation Project in the Seven Major Basins of China: Document Literature on the Key Management of the Gongshui River Basin in Jiangxi Province; Office of Soil and Water Conservation Committee of Jiangxi Province: Nanchang, China, 1997. (In Chinese)

24. Mann, H.B. Nonparametric tests against trend. Econometrica 1945, 13, 245-259. [CrossRef]

25. Kendall, M.G. Rank Correlation Methods; Charles Griffin: London, UK, 1975.

26. Bai, P.; Liu, W.H.; Guo, M.J. Impacts of climate variability and human activities on decrease in streamflow in the Qinhe River, China. Theor. Appl. Climatol. 2014, 117, 293-301. [CrossRef]

27. Jiang, C.; Zhang, L.; Li, D.; Li, F. Water discharge and sediment load changes in China: Change patterns, causes, and implications. Water 2015, 7, 5849-5875. [CrossRef]

28. Pettitt, A.N. A non-parametric approach to the change-point problem. J. R. Stat. Soc. Ser. C 1979, 28, $126-135$. [CrossRef]

29. Merriam, C.F. A comprehensive study of the rainfall on the Susquehanna Valley. Eos Trans. Am. Geophys. Union 1937, 18, 471-476. [CrossRef]

30. Searcy, J.K.; Hardison, C.H. Double-Mass Curves; Geological Survey Water Supply Paper: Washington, DC, USA, 1960.

31. Lu, X.; Wang, X.; Yang, C.; Liu, X.; Yang, Q. Changes and driving forces of the water-sediment relationship in the middle reaches of the Hanjiang River. Water 2018, 10, 887. [CrossRef]

32. Dahl, T.A.; Kendall, A.D.; Hyndman, D.W. Impacts of projected climate change on sediment yield and dredging costs. Hydrol. Process. 2018, 32, 1223-1234. [CrossRef]

33. Gao, G.Y.; Ma, Y.; Fu, B.J. Multi-temporal scale changes of streamflow and sediment load in a loess hilly watershed of China. Hydrol. Process. 2015, 30, 365-382. [CrossRef]

34. Wang, H.J.; Saito, Y.S.K.; Zhang, Y.; Bi, N.S.; Sun, X.X.; Yang, Z.S. Recent changes of sediment flux to the western Pacific Ocean from major rivers in East and Southeast Asia. Earth Sci. Rev. 2011, 108, 80-100. [CrossRef]

35. Walling, D.E. Human impact on land-ocean sediment transfer by the world's rivers. Geomorphology 2006, 79, 192-216. [CrossRef]

36. Meade, R.H.; Moody, G.A. Causes for the decline of suspended-sediment discharge in the Mississippi River system, 1940-2007. Hydrol. Process. 2010, 24, 35-49. [CrossRef]

(C) 2018 by the authors. Licensee MDPI, Basel, Switzerland. This article is an open access article distributed under the terms and conditions of the Creative Commons Attribution (CC BY) license (http:/ / creativecommons.org/licenses/by/4.0/). 